\title{
Relationship between BRAF V600E and clinical features in papillary thyroid carcinoma
}

\author{
Changjiao Yan*, Meiling Huang*, Xin Li, Ting Wang and Rui Ling \\ Department of Thyroid, Breast and Vascular Surgery, Xijing Hospital, Fourth Military Medical University, Xi'an, Shaanxi, China \\ Correspondence should be addressed to R Ling or T Wang: lingruiaoxue@126.com or ting_w100@126.com \\ *(C Yan and M Huang contributed equally to this work)
}

\begin{abstract}
Objective: To investigate the mutant status of BRAF gene and analyze its relationship to epidemiological risk factors and clinical outcomes among patients with papillary thyroid cancer (PTC) in the largest, single-institution Chinese cohort to date.

Methods: The medical records of 2048 PTC patients were reviewed in this retrospective study. Single-factor and multiple logistic regression analyses were applied to identify risk factors for BRAF V600E mutation. Survival outcomes including distant metastatic and persistent or recurrent PTC were examined, with a mean follow-up time of 23.4 (5-47) months.

Results: The BRAF V600E mutation was present in $83.7 \%$ of patients (1715 of 2048). Correlation was found between BRAF V600E mutation and several epidemiological features, including age, concomitant hypertension and Hashimoto thyroiditis (HT). For the clinicopathological features, BRAF V600E was significantly associated with bilateral multifocality (odds ratio (OR) 1.233, 95\% confidence interval (CI) 1.063-1.431, $P<0.01$ ) and less lateral lymph node metastases (OR $0.496,95 \% \mathrm{Cl} 0.357-0.689, P<0.01$ ). Smaller tumor size and advanced disease stage were significant in single-factor analyses but became insignificant after multivariate adjustment. No association was found between BRAF V600E mutation and extrathyroidal invasion, distant metastatic and disease persistence or recurrence.

Conclusion: Part of epidemiological features are independent risk or protective factors for BRAF V600E mutation. The presence of BRAF V600E mutation is not an aggressive prognosis on poor clinical outcomes in PTC. However, the high prevalence of BRAF V600E may provide guidance for surgery strategy and opportunity for targeted treatment in recurrent and advanced stage disease.
\end{abstract}

\author{
Key Words \\ - papillary thyroid cancer \\ - BRAFV600E \\ - epidemiological features \\ - clinicopathological features
}

\section{Introduction}

Thyroid cancer, especially papillary subtype, is the most common malignancy in the endocrine system (1). Papillary thyroid cancer (PTC) can be further classified into conventional variant (CPTC), follicular variant (FVPTC) and other rare variants (2). Despite PTC is usually a well-differentiated thyroid carcinoma with a favorable prognosis, its incidence has been sharply rising in many countries over the last decades (3) (the average incidence in the USA was $2.4 \%$ from 1980 to 1997 and $6.6 \%$ from 1997 to 2009 (2)). In addition, recurrence and metastases are common for a small proportion of PTCs who reach advanced disease stages (4). In recent years, molecular markers have received extensive attention to improving risk stratification of PTC (5).

$B R A F$ is the main subtype of RAF kinase and plays a key role in tumorigenesis. The mutation of BRAF V600E
Endocrine Connections (2019) 8, 988-996 
could trigger tumorigenesis through constitutively activating MAPK pathway (6). As the most common mutation observed in PTC, BRAF V600E has received special attention in various ethnic populations since this protein kinase may contribute to cell proliferation, growth and division. However, due to the limited large cohort evidence, the function of $B R A F \mathrm{~V} 600 \mathrm{E}$ as a biomarker in driving aggressiveness in PTC continues debatable (7, 8). The majority of researches claimed that BRAF V600E mutation was associated with poor clinicopathologic outcomes in patients with PTC, such as large tumor size, lymph node metastases, advanced clinical stages and recurrence $(9,10)$. By contrast, several studies suggested that BRAF V600E mutation had no significant association with clinical stage, multicentricity or recurrence (11, 12). These equivocal findings have hindered the fact that whether the mutation had an impact on aggressive behavior of PTC. Furthermore, most researches have focused on the relationship between mutation and clinicopathological characteristics, but the epidemiologic factors related to $B R A F \mathrm{~V} 600 \mathrm{E}$ mutations were rarely studied in previous researches. Here, we investigated epidemiological characteristics that may be associated with the mutation of BRAF V600E and then studied the role of BRAF V600E mutation in the clinicopathological features of PTC.

\section{Patients and methods}

\section{Patient identification and clinicopathologic data collection}

This study included 2048 patients (1556 women and 492 men) age $43.14 \pm 11.01$ years (mean \pm s.D.) who were diagnosed with PTC and underwent surgery between
January 2015 and July 2018 at the Department of the thyroid, breast and vascular surgery in Xijing Hospital. These patients were clinically observed with mean follow-up time of 23.4 months (range 5-47 months) after the initial treatments. All these patients were regularly followed with physical examinations, thyroid function tests and neck ultrasonography every 6-12 months after the initial surgery. If suspicious or indeterminate thyroid nodules or lymph nodes were found, ultrasound-guided fine-needle aspiration cytology (US-FNAC) was used for evaluation. Between January 2015 and July 2018, 2850 patients were diagnosed with thyroid cancer. Among these, 2805 patients (98.42\%) were diagnosed with PTC, and 45 patients (1.58\%) were diagnosed with other types of thyroid carcinoma. PTC patients without $B R A F$ V600E status or lost to follow-up were excluded. The flow diagram of patient included was shown in Fig. 1.

After institutional review board approval and informed patient consenting, we retrospectively collected detailed BRAF V600E and clinicopathologic data from institutional patient records. The epidemiological data and clinicopathological features were summarized in Tables 1 and 2, respectively. Patients with alcohol history was defined as patients who drinking more than twice a month and lasting more than 1 year. Patients with smoking history was defined as patients who had a current or past smoking history of $\geq 6$ months. Tumor node metastasis (TNM) stages were defined based on the seventh edition of the American Joint Committee on Cancer (AJCC) staging system. Persistent or recurrent disease was defined as the presence of a structural abnormality confirmed by cytological or surgical pathology after the initial surgery. The BRAF V600E mutation results had no influence on the treatment decision making.

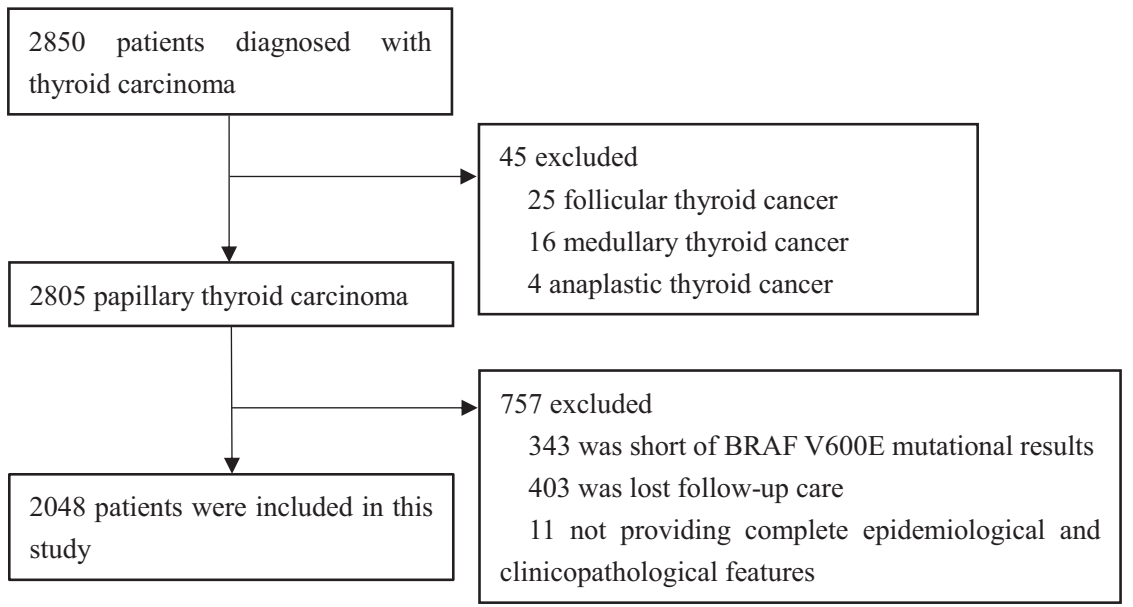

\section{Figure 1}

Flow diagram of patient included according to the inclusion and exclusion criteria. https://ec.bioscientifica.com https://doi.org/10.1530/EC-19-0246 (c) 2019 The authors Published by Bioscientifica Ltd

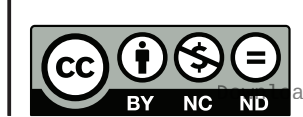

This work is licensed under a Creative Commons Attribution-NonCommercial-NoDerivatives 4.0 enternationad ticense ifica.com at 04/26/2023 08:27:02AM 
Table 1 Association of BRAF V600E with epidemiologic features of all PTC.

\begin{tabular}{|c|c|c|c|c|}
\hline & BRAF V600E mutation (-) & BRAF V600E mutation (+) & & \\
\hline & No. (\%) & No. (\%) & $\chi^{2}$ & $P$ value \\
\hline Total No. of cases & $333(16.3)$ & $1715(83.7)$ & & \\
\hline \multicolumn{5}{|l|}{ Age at diagnosis } \\
\hline$\leq 45$ & $224(20.3)$ & $881(79.7)$ & 28.366 & $<0.001$ \\
\hline$>45$ & $109(11.6)$ & $834(88.4)$ & & \\
\hline \multicolumn{5}{|l|}{ Sex } \\
\hline Male & $74(15.0)$ & $418(85.0)$ & 0.707 & 0.400 \\
\hline Female & $259(16.6)$ & $1297(83.4)$ & & \\
\hline \multicolumn{5}{|l|}{ Family history of cancer } \\
\hline $\begin{array}{l}\text { Had any family member(s) with history of } \\
\text { cancer }\end{array}$ & $27(11.4)$ & $209(88.6)$ & 4.550 & 0.033 \\
\hline None & $306(22.5)$ & $1506(77.5)$ & & \\
\hline \multicolumn{5}{|l|}{ Presence of history of cancer } \\
\hline Had any other cancer & $5(12.5)$ & 35 (87.5) & 0.424 & 0.515 \\
\hline None & $328(16.3)$ & $1680(83.7)$ & & \\
\hline \multicolumn{5}{|l|}{ Presence of smoking history } \\
\hline Ever & $28(18.1)$ & 127 (81.9) & 0.401 & 0.527 \\
\hline Never & $305(16.1)$ & $1588(83.9)$ & & \\
\hline \multicolumn{5}{|l|}{ Presence of alcohol history } \\
\hline Ever & $7(15.2)$ & $39(84.8)$ & 0.038 & 0.846 \\
\hline Never & $326(16.3)$ & $1676(83.7)$ & & \\
\hline \multicolumn{5}{|l|}{ Concomitant diabetes } \\
\hline Yes & $8(8.6)$ & 85 (91.4) & 4.196 & 0.041 \\
\hline No & $325(16.6)$ & $1630(83.4)$ & & \\
\hline \multicolumn{5}{|l|}{ Concomitant hypertension } \\
\hline Yes & $18(7.0)$ & $238(93.0)$ & 18.300 & $<0.001$ \\
\hline No & $315(17.6)$ & $1477(82.4)$ & & \\
\hline \multicolumn{5}{|l|}{ Concomitant benign thyroid diseases } \\
\hline \multicolumn{5}{|l|}{ Hyperthyroid } \\
\hline Yes & $7(24.1)$ & $22(75.9)$ & / & 0.305 \\
\hline No & $326(16.1)$ & $1693(83.9)$ & & \\
\hline \multicolumn{5}{|l|}{ Nodular goiter } \\
\hline Yes & $19(20.4)$ & 74 (79.6) & 1.244 & 0.265 \\
\hline No & $314(16.1)$ & 1641 (83.9) & & \\
\hline \multicolumn{5}{|l|}{$\mathrm{HT}$} \\
\hline Yes & 96 (28.9) & 236 (71.1) & 46.611 & $<0.001$ \\
\hline No & $237(13.8)$ & 1479 (86.2) & & \\
\hline
\end{tabular}

The chi-square test $\left(\chi^{2}\right.$ test) or, for small cell sizes, Fisher's exact test was employed to examine the significance of association between BRAF V600E and epidemiologic features. $P$ value $<0.05$ was treated as statistically significant. Bold indicates statistical significance.

'/' means no $\chi^{2}$ value because cell sizes were small and Fisher's exact test was employed. '\%' is the proportion of patients with or without BRAF V600E mutations in the subgroup of patients.

$H T$, Hashimoto thyroiditis.

\section{Mutational analyses}

BRAF V600E mutational analyses were performed by pathologists after surgical treatments of patients. DNA was isolated from formalin-fixed, paraffin-embedded (FFPE) tissue blocks by SDS-proteinase $\mathrm{K}$ method and subjected to Amplification Refractory Mutation System (ARMS)- real-time PCR for the detection of BRAF V600E mutations. DNA was extracted from each sample via a commercial kit (FFPE DNA reagent, Cat No. ADx-FF01) according to the manufacturer's instructions. Typically, $5 \mu \mathrm{m}$ sections (2-4 pieces) were carefully micro-dissected from FFPE tissue blocks. The sections were initially treated with $1.5 \mathrm{~mL}$ xylene/ethanol three times, then digested during an overnight incubation with $20 \mu \mathrm{L}$ proteinase $\mathrm{K}$ solution and $180 \mu \mathrm{L}$ buffer DTL in a $56^{\circ} \mathrm{C}$ rotating incubator, and DNA purification was performed through QIAgen columns, according to the manufacturer's instructions. Then, the most common T1799A transversion (BRAF V600E) mutation was studied. The PCR was used to amplify exon 15 of the BRAF gene, which was detected by BRAFV600 Mutations Detection Kit (Applied by ADx-BR01, AmoyDx Company, China) according to the manufacturer's instructions. PCR primer sequences were as follows: https://ec.bioscientifica.com https://doi.org/10.1530/EC-19-0246
(C) 2019 The authors Published by Bioscientifica Ltd
This work is licensed under a Creative Commons Attribution-NonCommercial-NoDerivatives 4.0 Internationab sicense.ifica . com at 04/26/2023 08:27:02AM 
Table 2 Relationship of BRAF V600E with clinicopathological features of All PTC.

\begin{tabular}{|c|c|c|c|c|}
\hline & BRAF V600E mutation (-) & BRAF V600E mutation $(+)$ & & \\
\hline & No. (\%) & No. $(\%)$ & $\chi^{2}$ & $P$ value \\
\hline Total no. of cases & $333(16.3)$ & $1715(83.7)$ & & \\
\hline \multicolumn{5}{|l|}{ Surgery } \\
\hline Lobectomy & $53(14.8)$ & 306 (85.2) & 0.716 & 0.397 \\
\hline Total thyroidectomy & $280(16.6)$ & 1409 (83.4) & & \\
\hline \multicolumn{5}{|l|}{ Histological type } \\
\hline СРTC & 321 (15.9) & $1701(84.1)$ & l & $<0.001$ \\
\hline FVPTC & $12(46.2)$ & $14(53.8)$ & & \\
\hline \multicolumn{5}{|l|}{ Tumor size } \\
\hline$\leq 2 \mathrm{~cm}$ & $290(15.6)$ & $1564(84.4)$ & 5.488 & 0.019 \\
\hline$>2 \mathrm{~cm}$ & 43 (22.2) & $151(77.8)$ & & \\
\hline Median (quartile), cm & $1.0(0.7-1.5)$ & $0.9(0.7-1.4)$ & & \\
\hline \multicolumn{5}{|l|}{ Lesions } \\
\hline Unilateral & $260(18.0)$ & $1184(82.0)$ & 10.959 & 0.001 \\
\hline Bilateral & $73(12.1)$ & 531 (87.9) & & \\
\hline \multicolumn{5}{|l|}{ Extrathyroidal invasion } \\
\hline Yes & 45 (15.6) & $244(84.4)$ & 0.117 & 0.732 \\
\hline No & $288(16.4)$ & $1471(83.6)$ & & \\
\hline \multicolumn{5}{|l|}{ Vascular invasion } \\
\hline Yes & $43(15.4)$ & 237 (84.6) & 0.194 & 0.660 \\
\hline No & $290(16.4)$ & $1478(83.6)$ & & \\
\hline \multicolumn{5}{|c|}{ Status of lymph node metastases ${ }^{a}$} \\
\hline Yes & $190(18.2)$ & $855(81.8)$ & 3.704 & 0.054 \\
\hline No & $127(14.9)$ & $727(85.1)$ & & \\
\hline \multicolumn{5}{|c|}{ Site of lymph node metastases } \\
\hline Only central & $92(14.0)$ & $564(86.0)$ & 20.648 & $<0.001$ \\
\hline Only lateral & $13(23.2)$ & $43(76.8)$ & & \\
\hline Central and lateral & $85(25.5)$ & $248(74.5)$ & & \\
\hline \multicolumn{5}{|c|}{ Disease stage (7th edition) ${ }^{\mathrm{b}}$} \\
\hline$I+I I$ & $282(17.8)$ & $1301(82.2)$ & 6.718 & 0.010 \\
\hline III + IV & $48(12.3)$ & 341 (87.7) & & \\
\hline \multicolumn{5}{|l|}{ Distant metastatic } \\
\hline Yes & $1(20.0)$ & $4(80.0)$ & / & 1.000 \\
\hline No & $332(16.3)$ & $1711(83.7)$ & & \\
\hline \multicolumn{5}{|c|}{ Persistent or recurrent disease } \\
\hline Yes & $19(22.1)$ & 67 (77.9) & 2.243 & 0.134 \\
\hline No & $314(16.0)$ & $1648(84.0)$ & & \\
\hline
\end{tabular}

The chi-square test ( $\chi^{2}$ test) or, for small cell sizes, Fisher's exact test was employed to examine the significance of association between BRAF V600E and clinicopathological features. $P$ value $<0.05$ was treated as statistically significant. Bold indicates statistical significance. Tumor size was summarized with medians (quartile).

'/'means no $\chi^{2}$ value because cell sizes were small and Fisher's exact test was employed. '\%' is the proportion of patients with or without BRAF V600E mutations in the subgroup of patients. 'a' means there are missing cases in 'Status of lymph node metastases'. In patients without BRAF V600E mutations, 16 patients had undetermined lymph node metastasis status. In patients with BRAF V600E mutations, 133 patients had undetermined lymph node metastasis status. ' $b$ ' means there are missing cases in 'Disease stage'. In patients without BRAF V600E mutations, the disease stage of three patients cannot be determined. In patients with BRAF V600E mutations, the disease stage of 73 patients cannot be determined.

CPTC, conventional papillary thyroid carcinoma; FVPTC, follicular variant papillary thyroid carcinoma.

forward primer, TCTGTAGCAGCCCTCAGTAGCGAAGCA GTGATTTTGGTCTAGCTACAGA; reverse primer, AGC CCTCAGTAGCGAAGCAACTCAGCAGCATCTCAGG. $B R A F$ gene reactions were performed in a final volume of $40 \mu \mathrm{L}$ using as template $10-15 \mathrm{ng}$ of genomic DNA, with $1 \times$ buffer including 14 pmol forward primer, 20 pmol reverse primer, $12.5 \mathrm{pmol}$ dNTPs, $350 \mathrm{pmol} \mathrm{MgCl}_{2}$, mutant probe $20 \mathrm{pmol}$ and 1 unit of Taq polymerase. Each reaction included a positive and a negative control sample, and in negative sample, DNA template was substituted by water. PCR recycling started with initial denaturation step at $95^{\circ} \mathrm{C}$ for $5 \mathrm{~min}$, followed by 40 cycles of denaturation $\left(95^{\circ} \mathrm{C}, 25 \mathrm{~s}\right)$, annealing $\left(64^{\circ} \mathrm{C}, 20 \mathrm{~s}\right)$ and extension $\left(72^{\circ} \mathrm{C}\right.$, $20 \mathrm{~s}$ ) and a last step of $10 \mathrm{~min}$ extension at $72^{\circ} \mathrm{C}$. PCR efficiency was determined by measuring the $\mathrm{Ct}$ value of FAM signal. https://ec.bioscientifica.com https://doi.org/10.1530/EC-19-0246 (c) 2019 The authors Published by Bioscientifica Ltd
This work is licensed under a Creative Commons Attribution-NonCommercial-NoDerivatives 4.0 elnternationab bicense.ifica.com at $04 / 26 / 2023$ 08:27:02AM 


\section{Statistical analyses}

Data related to histologic characteristics, patient epidemiological data and clinical outcomes were collected. Categorical data were summarized with frequencies and percentages. Continuous data were summarized with means \pm standard deviations (if it is a normal distribution) or medians and quartile (if it is not a normal distribution). The chi-square test ( $\chi^{2}$ test) or, for small cell sizes, Fisher's exact test was employed to examine categorical variables. All $P$ values were two-sided, and a $P$ value $<0.05$ was treated as statistically significant. Pooled ORs with their corresponding 95\% confidence intervals (95\% CIs) were calculated to assess the relationship between BRAF V600E mutation and clinicopathological features. All statistical analyses were conducted by the software of SPSS with version 23.0.

\section{Results}

\section{BRAF V600E mutation in PTC}

There were 2048 patients included in the study with an average age of $43.14 \pm 11.01$ (range $5-80$ ), and $76.0 \%$ of the patients were female (1556 women and 492 men). BRAF V600E mutation was found in 1701 of 2022 (84.1\%) CPTCs, and 14 of 26 (53.8\%) FVPTCs, with an overall prevalence of $83.7 \%$ (1715 of 2048). No significant difference of BRAF V600E mutation was observed in female and male patients $(P=0.400)$. With regard to ages, significant difference of $B R A F$ V600E incidence was found between patients aged $\leq 45$ and $>45$ years (79.7 vs $88.4 \%, P<0.001$ ). To further investigate the influence of age on mutational incidence, we divided all patients into children/adolescent group ( $\leq 25$ years) and adults groups of various age ranges $(25-35,35-45,45-55$, $>55$ years old). As shown in Fig. 2, patients were more prone to be BRAF V600E positive with the growth of age.

\section{Association of BRAF V600E and epidemiological features in PTCs}

To identify epidemiological factors associated with $B R A F$ V600E mutation, the relationship between epidemiological features and the mutation was investigated. In the univariate analysis of 2048 PTCs (Table 1), the presence of BRAF V600E mutation was found to be significantly associated with several epidemiological features, including age at diagnosis, family history of cancer, concomitant diabetes, hypertension and Hashimoto

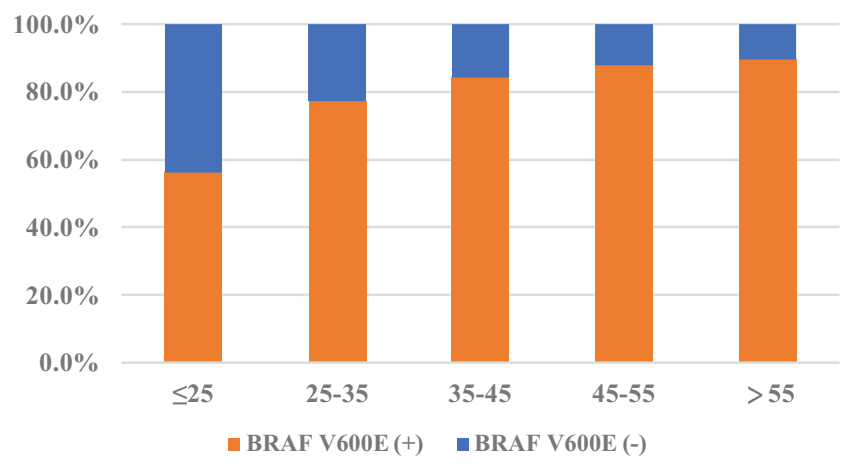

\section{Figure 2}

The correlation between the presence of the BRAF V600E mutation and the age of patients at the time of diagnosis.

thyroiditis (HT). The incidence of BRAF V600E mutations in patients with family cancer history was higher than that in patients without family history of cancer (88.6 vs $77.5 \%, P=0.033)$. Interestingly, patients with diabetes or hypertension presented higher mutation rates than those who did not have diabetes or hypertension (91.4 vs $83.4 \%, P=0.041 ; 93.0$ vs $82.4 \%, P<0.001)$. Conversely, the patients concomitant of HT displayed less BRAF V600E mutations than patients without HT (71.1 vs $86.2 \%, P<0.001)$. Similarly, patients with hyperthyroid or nodular goiter showed lower mutation frequency than those who did not have hyperthyroid or nodular goiter, but the association was insignificant. Except the factors mentioned above, no significant association was found between the presence of BRAF V600E mutation and other features including gender, presence of history of cancer, presence of smoking and alcohol history.

\section{Relationship of BRAF V600E and clinicopathological features in PTCs}

In the univariate analysis of all PTCs (Table 2), the presence of BRAF V600E was found to be significantly associated with small tumor size $(P=0.019)$, bilateral multifocality $(P=0.001)$, less central and lateral lymph node metastases simultaneously $(P<0.001)$ and advanced disease stage (III and IV) $(P=0.010)$. Although there was no significant association, less BRAF V600E mutation was found in patients with lymph node metastases than patients without lymph node metastases ( 81.8 vs $85.1 \%$, $P=0.054)$. Furthermore, it was worth noticing that less $B R A F$ V600E presented in patients with aggressive lymph node metastases (central and lateral metastases at the same time) than patients with only central or only lateral lymph node metastases ( 74.5 vs $86.0 \%$ or $76.8 \%, P<0.001$ ). No significant association was found between $B R A F$ 
V600E mutation and another high-risk clinicopathologic characteristics, such as extrathyroidal invasion $(P=0.732)$, vascular invasion $(P=0.660)$, distant metastatic $(P=1.000)$ and PTC persistence or recurrence $(P=0.134)$.

\section{Multivariate logistic regression analysis of $B R A F$ V600E mutation in PTCs}

To further confirm the relationship between BRAF V600E and epidemiological or clinicopathological features, multivariate logistic regression analysis was performed (Table 3$)$. The results showed that age $(P=0.002, \mathrm{OR}=1.024$, 95\% CI=1.009-1.041), concomitant hypertension $(P=0.032, \mathrm{OR}=1.812,95 \% \mathrm{CI}=1.052-3.120)$ and lesions $(P=0.006, \quad \mathrm{OR}=1.233, \quad 95 \% \quad \mathrm{CI}=1.063-1.431) \quad$ were positive independent factors for $B R A F$ V600E mutation. In contrast, concomitant HT $(P<0.001, \mathrm{OR}=0.402,95 \%$ $\mathrm{CI}=0.300-0.538)$ and lateral lymph node metastases
$(P<0.001, \quad \mathrm{OR}=0.496, \quad 95 \% \quad \mathrm{CI}=0.357-0.689) \quad$ were negative independent factors for $B R A F \mathrm{~V} 600 \mathrm{E}$ mutation. After adjustment for patients' age and sex, the association between BRAF V600E mutation and disease stage was not statistically significant $(P=0.771, \quad O R=1.028$, 95\% CI $=0.856-1.234)$.

\section{Discussion}

This study sought to find the epidemiological factors associated with BRAF V600E mutation and clarify the relationship between $B R A F$ V600E mutation and clinical outcomes in PTC. Previously, the BRAF V600E mutation has been reported as an aggressive prognosis in PTC, although a large cohort study was inadequate and there have been noteworthy inconsistencies in some studies $(13,14)$. In our analysis, we found a lack of

Table 3 Multivariate logistic regression analysis of BRAF V600E mutation of all PTC.

\begin{tabular}{|c|c|c|c|c|c|}
\hline & \multicolumn{2}{|c|}{ BRAF V600E mutation $(n, \%)$} & \multirow[b]{2}{*}{ P Value } & \multirow[b]{2}{*}{ OR } & \multirow[b]{2}{*}{$95 \% \mathrm{Cl}$} \\
\hline & - & + & & & \\
\hline Age at diagnosis & $39.29 \pm 11.44$ & $43.88 \pm 10.77$ & 0.002 & 1.024 & $1.009-1.041$ \\
\hline Sex & & & 0.750 & 1.051 & $0.773-1.431$ \\
\hline Male & $74(15.0 \%)$ & $418(85.0 \%)$ & & & \\
\hline Female & $259(16.6 \%)$ & $1297(83.4 \%)$ & & & \\
\hline Family history of cancer & & & 0.195 & 1.352 & $0.857-2.131$ \\
\hline $\begin{array}{l}\text { Had any family member(s) with } \\
\text { history of cancer }\end{array}$ & $27(11.4 \%)$ & $209(88.6 \%)$ & & & \\
\hline None & $306(22.5 \%)$ & $1506(77.5 \%)$ & & & \\
\hline Concomitant diabetes & & & 0.428 & 1.389 & $0.616-3.129$ \\
\hline Yes & $8(8.6 \%)$ & $85(91.4 \%)$ & & & \\
\hline No & $325(16.6 \%)$ & $1630(83.4 \%)$ & & & \\
\hline Concomitant hypertension & & & 0.032 & 1.812 & $1.052-3.120$ \\
\hline Yes & $18(7.0 \%)$ & $238(93.0 \%)$ & & & \\
\hline No & $315(17.6 \%)$ & $1477(82.4 \%)$ & & & \\
\hline Concomitant HT & & & $<0.001$ & 0.402 & $0.300-0.538$ \\
\hline Yes & $96(28.9 \%)$ & $236(71.1 \%)$ & & & \\
\hline No & $237(13.8 \%)$ & $1479(86.2 \%)$ & & & \\
\hline Tumor size & $1.0(0.7-1.5)$ & $0.9(0.7-1.4)$ & 0.571 & 0.950 & $0.795-1.135$ \\
\hline Lesions & & & 0.006 & 1.233 & $1.063-1.431$ \\
\hline Unilateral & $260(18.0 \%)$ & $1184(82.0 \%)$ & & & \\
\hline Bilateral & $73(12.1 \%)$ & $531(87.9 \%)$ & & & \\
\hline \multicolumn{6}{|l|}{ Site of lymph node metastasis } \\
\hline Central & $177(17.9 \%)$ & $811(82.1 \%)$ & 0.346 & 1.157 & $0.854-1.568$ \\
\hline Lateral & $98(25.2 \%)$ & $290(74.8 \%)$ & $<0.001$ & 0.496 & $0.357-0.689$ \\
\hline Disease stage (7th edition) ${ }^{a}$ & & & 0.771 & 1.028 & $0.856-1.234$ \\
\hline I + II & $282(17.8 \%)$ & $1301(82.2 \%)$ & & & \\
\hline III + IV & $48(12.3 \%)$ & 341 (87.7\%) & & & \\
\hline
\end{tabular}

Age at diagnosis was summarized with means \pm standard deviations. Tumor size was summarized with medians (quartile). Multivariate logistic regression analysis was employed to identify risk factors for BRAF V600E mutations. $P$ value $<0.05$ was treated as statistically significant. Bold indicates statistical significance.

'\%' is the proportion of patients with or without BRAF V600E mutations in the subgroup of patients. 'a' means there are missing cases in 'Disease stage'. In patients without BRAF V600E mutations, the disease stage of three patients cannot be determined. In patients with BRAF V600E mutations, the disease stage of 73 patients cannot be determined.

HT, Hashimoto thyroiditis; OR, odds ratio; $95 \% \mathrm{Cl}, 95 \%$ confidence interval.

https://ec.bioscientifica.com https://doi.org/10.1530/EC-19-0246 (c) 2019 The authors Published by Bioscientifica Ltd

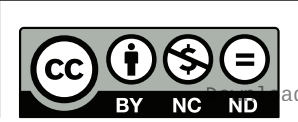

This work is licensed under a Creative Commons Attribution-NonCommercial-NoDerivatives 4.0 Internationab ticense.ifica.com at 04/26/2023 08:27:02AM 
correlation between $B R A F$ V600E mutation and either aggressive clinicopathological features or persistent or recurrent disease.

The incidence of $B R A F$ V600E mutation increased in recent years, it seems that BRAF V600E mutation gradually become the accompanying phenomenon for PTC patients. Mingzhao Xing et al. reported BRAF V600E rate of 38.3\% in patients between 1990 and 2012 (15). In 2007, Electron et al. reported the prevalence of $B R A F$ V600E was 46.4\% (16). In 2012, Kurtulmus et al. showed $B R A F$ V600E mutation rate of $39.45 \%$ in PTCs (17). The meta-analysis showed BRAF V600E mutations occurred in $60.6 \%$ of PTCs (update to August, 2015) (6). In 2016, Kim et al. reported BRAF V600E mutations were presented in $83.7 \%$ PTC patients (2789 of 3332) (18), and we found the similar mutation rate in our sample. Compared to previous researches, we update $B R A F$ V600E mutation data from 2015 to 2018. The reason why mutation prevalence in our study is higher than the average may ascribe to population aging in recent years and different research methodology. In this study, the BRAF V600E mutations were tested from the postoperative tissue samples using the ARMS- realtime PCR method, which was more sensitive and robust at detecting BRAF V600E somatic mutations than DNA sequencing on clinical samples (19).

Our study indicated that older age and concomitant hypertension were independent risk factors of $B R A F$ V600E mutation. On the contrary, concomitant HT was an independent protective factor of the mutation. Despite being insignificant after multivariate adjustment, the presence of family history of cancer was associated with higher $B R A F$ V600E mutation incidence in the univariate analysis, which were in agreement with the data reported in previous study (20). In addition, with the large size of this study, negative correlation between HT and BRAF V600E mutation was demonstrated, which was confirmed in a recent smaller study (21). Potential mechanisms and immunological link that might lead to the synchronous appearance of HT and PTC had been investigated $(22,23)$. If there is more clinical evidence, the correlation between $B R A F$ V600E and family history of cancer, hypertension and HT may help to promote the investigation of $B R A F$ V600E mutation mechanism. As for the factor of age, plenty of researches had found that incidence of $B R A F$ V600E was higher in patients $>45$ years old $(10,16)$, but few studies found the positive correlation between $B R A F$ V600E and age (Fig. 2). Compared to adults, PTC in pediatric and adolescents presents more lymph node metastases, distant metastases and recurrence $(24,25)$. Combining the study mentioned above, the phenomenon that less number of $B R A F$ V600E mutations appears in patients aged under 25 years suggested that aggressive features displayed in these patients may not be caused by $B R A F$ V600E mutation.

The aggressive role of $B R A F$ V600E mutations has been widely investigated in previous studies $(6,8,10)$. However, our results did not show that BRAF V600E mutation is a biomarker in driving aggressiveness. Given the high and increased prevalence of $B R A F$ V600E mutation in recent years $(60.6 \%$, on average, in the meta-analysis mentioned above (6), and $83.7 \%$ in our study), and the oppositely indolent behavior, the rarity recurrence and mortality of PTC (16 and 3\%, respectively) $(26,27)$, an absence of association between $B R A F$ V600E mutation, and these negative events seem logical. In univariate analyses, BRAF V600E mutations were significantly associated with smaller tumor, bilateral multifocality, advanced disease stage and less aggressive lymph node metastases in PTCs. Advanced TNM stage showed insignificant after multivariate adjustment. Therefore, bilateral multifocality seems to be the only risk factor associated with $B R A F$ V600E. Notably, a recent study showed tumor multifocality has no independent risk prognostic value in outcomes of PTC (28). Other classic risk factors (29), such as extrathyroidal extension, distant metastases and disease recurrence, were insignificantly associated with BRAF V600E mutation. Therefore, presence of $B R A F \mathrm{~V} 600 \mathrm{E}$ is not an aggressive role associated with poor clinicopathologic outcomes in PTC. A recent publication has called into question the relationship of $B R A F \mathrm{~V} 600 \mathrm{E}$ mutation and prognosis in PTC. In the analysis of 508 patients with $B R A F$ V600E mutation, Henke et al. found the mutation is not predictive of long-term outcome in PTC (7).

Although the presence of $B R A F$ V600E mutation is not an aggressive prognosis on poor clinical outcomes, surgery strategy and treatment guided by the presence of the mutation may be available. Such therapies might include determining surgery extent and the use of $B R A F$ inhibitors. The association between $B R A F$ V600E and bilateral lesions and less lateral lymph node metastases was found in our study. If there is more clinical evidence in the future, the status of BRAF V600E mutation may be considered as one of the factors for determining the surgery extent besides tumor size, extrathyroidal extension, vascular invasion, lymph node size and willingness of patients (30). Furthermore, considerable patients with BRAF V600E mutation will have recurrence since a majority of PTC patients in our cohort $(83.7 \%)$ had the mutation. We propose that high-risk patients with BRAF V600E 
mutation use BRAF inhibitors, such as sorafenib, lenvatinib and vemurafenib. Those patients might benefit from the targeted therapy, which (sorafenib and lenvatinib) have been approved for metastatic PTC (31).

The greatest strengths of this study are its consecutive large cohort (2048 PTC patients) and its latest research time (from 2015 to 2018). The limitations of this study were as follows. First, a selection bias could occur in this retrospective unicentral research. The large consecutive cohort of patients may help minimize the bias. Second, follow-up time was short in this study (mean 23.4 months, range, 5-47 months). And research on the mechanism of epidemiological features associated with BRAF V600E mutation in PTCs should be carried out in the future.

In summary, this was a large consecutive retrospective study that investigated the relationship of BRAF V600E mutation with epidemiological and clinicopathological features. Older age and concomitant hypertension were independent risk factors of BRAF V600E mutation. Concomitant HT was an independent protective factor for the BRAF V600E expression. Bilateral multifocality was the only risk factor associated with $B R A F$ V600E but a recent study showed it has no independent risk prognostic value in outcomes of PTC. Other poor clinicopathological features were insignificantly associated with the mutation. Although the presence of BRAF V600E mutation is not an aggressive prognosis on poor clinical outcomes, surgery and treatment guided by the presence of the mutation may be available.

\section{Declaration of interest}

The authors declare that there is no conflict of interest that could be perceived as prejudicing the impartiality of the research reported.

\section{Funding}

The authors would like to acknowledge support from the National Natural Science Foundation of China (No. 81572917).

\section{Ethical approval}

Consent has been obtained from each patient after full explanation of the purpose and nature of all procedures used. The study was approved by an independent ethics committee of Xijing Hospital (first affiliated hospital of Fourth Military Medical University).

\section{References}

1 Pacini F \& Castagna MG. Approach to and treatment of differentiated thyroid carcinoma. Medical Clinics of North America 201296 369-383. (https://doi.org/10.1016/j.mcna.2012.01.002)

2 Pellegriti G, Frasca F, Regalbuto C, Squatrito S \& Vigneri R. Worldwide increasing incidence of thyroid cancer: update on epidemiology and risk factors. Journal of Cancer Epidemiology 2013 2013 965212. (https://doi.org/10.1155/2013/965212)

3 Jung CK, Little MP, Lubin JH, Brenner AV, Wells SA, Jr, Sigurdson AJ \& Nikiforov YE. The increase in thyroid cancer incidence during the last four decades is accompanied by a high frequency of BRAF mutations and a sharp increase in RAS mutations. Journal of Clinical Endocrinology and Metabolism 201499 E276-E285. (https://doi. org/10.1210/jc.2013-2503)

4 Vuong HG, Altibi AM, Abdelhamid AH, Ngoc PU, Quan VD, Tantawi MY, Elfil M, Vu TL, Elgebaly A, Oishi N, et al. The changing characteristics and molecular profiles of papillary thyroid carcinoma over time: a systematic review. Oncotarget 20178 10637-10649. (https://doi.org/10.18632/oncotarget.12885)

5 Nikiforov YE \& Nikiforova MN. Molecular genetics and diagnosis of thyroid cancer. Nature Reviews: Endocrinology 20117 569-580. (https://doi.org/10.1038/nrendo.2011.142)

6 Zhang Q, Liu SZ, Zhang Q, Guan YX, Chen QJ \& Zhu QY. Metaanalyses of association between BRAF(V600E) mutation and clinicopathological features of papillary thyroid carcinoma. Cellular Physiology and Biochemistry 201638 763-776. (https://doi. org/10.1159/000443032)

7 Henke LE, Pfeifer JD, Ma C, Perkins SM, DeWees T, El-Mofty S, Moley JF, Nussenbaum B, Haughey BH, Baranski TJ, et al. BRAF mutation is not predictive of long-term outcome in papillary thyroid carcinoma. Cancer Medicine 20154 791-799. (https://doi. org/10.1002/cam4.417)

8 Tufano RP, Teixeira GV, Bishop J, Carson KA \& Xing M. BRAF mutation in papillary thyroid cancer and its value in tailoring initial treatment: a systematic review and metaanalysis. Medicine 201291 274-286. (https://doi.org/10.1097/ MD.0b013e31826a9c71)

9 Xing M, Westra WH, Tufano RP, Cohen Y, Rosenbaum E, Rhoden KJ, Carson KA, Vasko V, Larin A, Tallini G, et al. BRAF mutation predicts a poorer clinical prognosis for papillary thyroid cancer. Journal of Clinical Endocrinology and Metabolism 200590 6373-6379. (https:// doi.org/10.1210/jc.2005-0987)

10 Kim TH, Park YJ, Lim JA, Ahn HY, Lee EK, Lee YJ, Kim KW, Hahn SK, Youn YK, Kim KH, et al. The association of the BRAF(V600E) mutation with prognostic factors and poor clinical outcome in papillary thyroid cancer: a meta-analysis. Cancer 2012118 1764-1773. (https://doi.org/10.1002/cncr.26500)

11 Walczyk A, Kowalska A, Kowalik A, Sygut J, Wypiorkiewicz E, Chodurska R, Pieciak L \& Gozdz S. The BRAF(V600E) mutation in papillary thyroid microcarcinoma: does the mutation have an impact on clinical outcome? Clinical Endocrinology 201480 899-904. (https://doi.org/10.1111/cen.12386)

12 Nam JK, Jung CK, Song BJ, Lim DJ, Chae BJ, Lee NS, Park WC, Kim JS, Jung SS \& Bae JS. Is the BRAF(V600E) mutation useful as a predictor of preoperative risk in papillary thyroid cancer? American Journal of Surgery 2012203 436-441. (https://doi.org/10.1016/j. amjsurg.2011.02.013)

13 Russo M, Malandrino P, Nicolosi ML, Manusia M, Marturano I, Trovato MA, Pellegriti G, Frasca F \& Vigneri R. The BRAF(V600E) mutation influences the short- and medium-term outcomes of classic papillary thyroid cancer, but is not an independent predictor of unfavorable outcome. Thyroid 201424 1267-1274. (https://doi. org/10.1089/thy.2013.0675)

14 Gandolfi G, Sancisi V, Piana S \& Ciarrocchi A. Time to re-consider the meaning of BRAF V600E mutation in papillary thyroid carcinoma International Journal of Cancer 2015137 1001-1011. (https://doi. org/10.1002/ijc.28976)

15 Xing M, Liu R, Liu X, Murugan AK, Zhu G, Zeiger MA, Pai S \& Bishop J. BRAF V600E and tert promoter mutations cooperatively identify the most aggressive papillary thyroid cancer with highest recurrence. Journal of Clinical Oncology 201432 2718-2726. (https:// doi.org/10.1200/JCO.2014.55.5094) 
16 Kebebew E, Weng J, Bauer J, Ranvier G, Clark OH, Duh QY, Shibru D, Bastian B \& Griffin A. The prevalence and prognostic value of BRAF mutation in thyroid cancer. Annals of Surgery 2007246 466-470; discussion 70-71. (https://doi.org/10.1097/ SLA.0b013e318148563d)

17 Kurtulmus N, Duren M, Ince U, Cengiz Yakicier M, Peker O, Aydin O, Altiok E, Giray S, Azizlerli H. BRAF(V600E) mutation in Turkish patients with papillary thyroid cancer: strong correlation with indicators of tumor aggressiveness. Endocrine 201242 404-410. (https://doi.org/10.1007/s12020-012-9651-x)

18 Kim SK, Woo JW, Lee JH, Park I, Choe JH, Kim JH \& Kim JS. Chronic lymphocytic thyroiditis and BRAF V600E in papillary thyroid carcinoma. Endocrine-Related Cancer 201623 27-34. (https://doi. org/10.1530/ERC-15-0408)

19 Ellison G, Donald E, McWalter G, Knight L, Fletcher L, Sherwood J, Cantarini M, Orr M \& Speake G. A comparison of ARMS and DNA sequencing for mutation analysis in clinical biopsy samples. Journal of Experimental and Clinical Cancer Research 201029 132. (https://doi. org/10.1186/1756-9966-29-132)

20 Zhang Q, Song F, Zheng H, Zhu X, Song F, Yao X, Zhang L \& Chen K. Association between single-nucleotide polymorphisms of BRAF and papillary thyroid carcinoma in a Chinese population. Thyroid 2013 23 38-44. (https://doi.org/10.1089/thy.2012.0228)

21 Zeng RC, Jin LP, Chen ED, Dong SY, Cai YF, Huang GL, Li Q, Jin C, Zhang XH \& Wang OC. Potential relationship between Hashimoto's thyroiditis and BRAF(V600E) mutation status in papillary thyroid cancer. Head and Neck 201638 (Supplement 1) E1019-E1025. (https://doi.org/10.1002/hed.24149)

22 Ehlers M \& Schott M. Hashimoto's thyroiditis and papillary thyroid cancer: are they immunologically linked? Trends in Endocrinology and Metabolism 201425 656-664. (https://doi.org/10.1016/j. tem.2014.09.001)

23 Boi F, Pani F \& Mariotti S. Thyroid autoimmunity and thyroid cancer: review focused on cytological studies. European Thyroid Journal 20176 178-186. (https://doi.org/10.1159/000468928)

24 Spinelli C, Rossi L, Piscioneri J, Strambi S, Antonelli A, Ferrari A, Massimino M \& Miccoli P. Pediatric differentiated thyroid cancer: when to perform conservative and radical surgery. Current Pediatric
Reviews 201612 247-252. (https://doi.org/10.2174/15733963126661 61014092023

25 Al-Qurayshi Z, Hauch A, Srivastav S, Aslam R, Friedlander P \& Kandil E. A national perspective of the risk, presentation, and outcomes of pediatric thyroid cancer. JAMA Otolaryngology: Head and Neck Surgery 2016142 472-478. (https://doi.org/10.1001/ jamaoto.2016.0104)

26 Xing M, Alzahrani AS, Carson KA, Shong YK, Kim TY, Viola D, Elisei R, Bendlova B, Yip L, Mian C, et al. Association between BRAF V600E mutation and recurrence of papillary thyroid cancer. Journal of Clinical Oncology 201533 42-50. (https:/doi.org/10.1200/ JCO.2014.56.8253)

27 Xing M, Alzahrani AS, Carson KA, Viola D, Elisei R, Bendlova B, Yip L, Mian C, Vianello F, Tuttle RM, et al. Association between BRAF V600E mutation and mortality in patients with papillary thyroid cancer. JAMA 2013309 1493-1501. (https://doi.org/10.1001/ jama.2013.3190)

28 Wang F, Yu X, Shen X, Zhu G, Huang Y, Liu R, Viola D, Elisei R, Puxeddu E, Fugazzola L, et al. The prognostic value of tumor multifocality in clinical outcomes of papillary thyroid cancer. Journal of Clinical Endocrinology and Metabolism 2017102 3241-3250. (https://doi.org/10.1210/jc.2017-00277)

29 Haugen BR, Alexander EK, Bible KC, Doherty GM, Mandel SJ, Nikiforov YE, Pacini F, Randolph GW, Sawka AM, Schlumberger, et al. 2015 American Thyroid Association management guidelines for adult patients with thyroid nodules and differentiated thyroid cancer: the American Thyroid Association Guidelines Task Force on Thyroid Nodules and Differentiated Thyroid Cancer. Thyroid 201626 1-133. (https://doi.org/10.1089/thy.2015.0020)

30 Wang TS \& Sosa JA. Thyroid surgery for differentiated thyroid cancer - recent advances and future directions. Nature Reviews: Endocrinology 201814 670-683. (https://doi.org/10.1038/s41574-018-0080-7)

31 Brose MS, Nutting CM, Jarzab B, Elisei R, Siena S, Bastholt L, de la Fouchardiere C, Pacini F, Paschke R, Shong YK, et al. Sorafenib in radioactive iodine-refractory, locally advanced or metastatic differentiated thyroid cancer: a randomised, double-blind, phase 3 trial. Lancet 2014384 319-328. (https://doi.org/10.1016/S01406736(14)60421-9)

Received in final form 9 June 2019

Accepted 17 June 2019

Accepted Preprint published online 17 June 2019 https://ec.bioscientifica.com https://doi.org/10.1530/EC-19-0246 (c) 2019 The authors Published by Bioscientifica Ltd
This work is licensed under a Creative Commons Attribution-NonCommercial-NoDerivatives 4.0 Internationab ticense ifica . com at $04 / 26 / 2023$ 08:27:02Am 